\title{
A Model for Designing Geocollaborative Artifacts and Applications
}

\author{
Pedro Antunes ${ }^{1}$, Gustavo Zurita ${ }^{2}$, and Nelson Baloian ${ }^{3}$ \\ ${ }^{1}$ University of Lisbon, \\ Department of Informatics of the Faculty of Sciences, Campo Grande, Lisbon, Portugal \\ paa@di.fc.ul.pt \\ ${ }^{2}$ Universidad de Chile, \\ Department of Information System and Management of the Economy and Businesses \\ School, Diagonal Paraguay 257, Santiago de Chile, Chile \\ gzurita@ing.puc.cl \\ ${ }^{3}$ Universidad de Chile, \\ Department of Computer Science of the Engineering School, Blanco Encalada 2120, \\ Santiago de Chile, Chile \\ nbaloian@gmail.com
}

\begin{abstract}
There are many human activities for which information about the geographical location where they take place is of paramount importance. In the last years there has been increasing interest in the combination of Computer Supported Collaborative Work (CSCW) and geographical information. In this paper we analyze the concepts and elements of CSCW that are most relevant to geocollaboration. We define a model facilitating the design of shared artifacts capable to build shared awareness of the geographical context. The paper also describes two case studies using the model to design geocollaborative applications.
\end{abstract}

Key words: Geocollaboration, sensemaking, collaborative capacity.

\section{Introduction}

Since thousands of years mankind has used maps printed in stone, textile, papyrus and paper to support various tasks involving navigation. Nowadays, we use a great variety of electronic devices like handhelds and Tablet-PCs to accomplish the same purpose. Smartboards and other interactive large multi-touch displays allow virtual navigation on 3D maps. And people locate physical landmarks using mobile devices and GPSs. Furthermore, the widespread availability of mobile and wireless technology, combined with advances made in human-computer interaction, user-interfaces and visualization, turn possible the computer support to multifaceted activities requiring geospatial information and collaboration, also known as geocollaboration.

According to [1-3], geocollaboration is a complex computer supported collaborative working situation where people execute diverse tasks using geospacial information. These tasks may involve exploring [2] and/or interpreting geographically-related data [4], mapping data into meaningful representations [5], and 
taking geospacial decisions in various kinds of situations, like crisis management [6, $7]$, building planning, knowledge creation and management [8, 9], and strategy making [10]. Thus geocolaboration may be defined as the study of collaborative tasks where the information concerning location plays a fundamental role, as well as the development of methods, tools and frameworks facilitating these activities.

A central issue in geocolaboration concerns modeling the collaborative tasks performed by a group of people and involving geospacial information. This activity requires conceptualizing work scenarios around different modalities of time, place, space and context.

There have been some conceptual framework proposals addressing some of the mentioned modalities in specific application scenarios like crisis management, policy creation on-the-field, urban planning [3], military strategy, and mining exploration [1]. The role of these frameworks is to facilitate the application design according to a comprehensive set of technological, social and cognitive requirements. In this paper we organize all these elements in a generic framework which main purpose is also to facilitate application design and development.

\section{CSCW Concepts Used in Geocolaboration}

The notion of place has been considered fundamental to understand CSCW. The time/place map proposed by Johansen et al [11] has been one of the most prevalent CSCW taxonomies in the research literature (see, e.g. [12]). The distinction between same-place and different-place has a focus on accessibility rather than geographical nature, determining the overall architecture and functionality of the system. In particular, the time/place map is based upon the discussion of DeSanctis and Gallupe [13] about the different support to remote and local groups.

Some subsequent developments of the time/place map continue to emphasize the accessibility constraints. For instance, the expansion of the place dimension in three categories - co-located, virtual co-located and remote -, addresses the infrastructure capabilities to access each other in a team [14-16].

Going beyond the accessibility constraints imposed by the technology, place has also been regarded by social theorists as a fundamental constraint to communication. Studies of media richness [17] and media naturalness [18] show that communication mediated by technology looses several important features such as nonverbal cues, rapid feedback and arousal. In this line of reasoning, the notion of place is fundamental to adapt the medium to the group and task, and conversely adapt the group and task to the medium.

The conceptual change from place to space introduces a more broad concern with geographical relationships such as location, distance and orientation [19, 20]. Places exist in spaces [20, 21]. Dix et al [19] proposed a taxonomy of space considering physical and virtual places, and Cartesian and topological locations.

Rodden [22] analyzed the relationships between context, places and spaces. He proposed a conceptual model of virtual spaces using focus and nimbus. Focus and nimbus are subspaces that, respectively, map the attention and presence of elements in spaces. Also related with context, we find the distinction between private and public 
spaces, the former pertaining to things and actions belonging to one single individual and the later shared among a group $[8,23]$.

The notion of virtual space is fundamental in Collaborative Virtual Environments [24]. Virtual spaces are interactive, shared, malleable, populated and may be navigated. According to MacEachren and Brewer [12], interaction involves the aggregation of participants, topology of connections and dissemination of information. The navigation is not necessarily spatial but may also be logical. For instance, the rooms-metaphor defines navigation in virtual spaces like discussion forums [25] that are not spatially organized but rather organized according to the associated set of activities. Virtual spaces may assume complex structures, such as clusters, stacks, lists, tables, rooms, etc. [26]. Users should then be able to navigate these structures. Collaborative visualization, as an enabler of interaction and collaboration, is naturally another major challenge to consider in virtual spaces [8, 27]. Collaborative visualization involves at least data exchange, shared control and dynamic interaction [12].

Concerning the relationship between physical space and navigation, we also find in the literature the distinction between wandering, visiting and traveling [28]. In the same line of reasoning, Dix et al [19] proposed different levels of mobility: fixed, mobile, autonomous, free, embedded and pervasive. Cheverst et al [29] studied the relationships between mobility, location awareness and location services to derive important requirements such as flexibility, visibility and context-sensitivity. Davis [30] analyzed the challenges posed by the relationship between mobility and information access, including the removal of time/space constraints to communication and knowledge work, improved access to decision makers and increased ability to receive and process information.

We should also analyze the notion of workspace. According to Snowdon et al [24], a place has inherent a set of activities that occur there, while a workspace is just a container of places with ongoing activities. We may distinguish two categories of workspaces: structured and georeferenced workspaces.

The structured workspace organizes (logically or physically) several activities in coherent sets, which are nevertheless independent from the place itself. A group editor is a good example of this type of workspace, since the workspace serves to organize different activities, like writing and revising, while maintaining a coherent view of the whole [31].

Liechti [32] studied the relationship between context and workspace, defining peripheral awareness as the understanding of the activities being carried out by others nearby one's place. Peripheral awareness is naturally related with the notions of focus and nimbus, but also with notification and attention. Gutwin and Greenberg [33] expanded this view to account for the whole space, defining workspace awareness as the understanding of another person interactions in a shared workspace using a basic set of questions: who, what, where, when, and how.

A georeferenced workspace organizes activities dependent on the geographical place where they are carried out. We find in the literature innumerous examples of georeferenced workspaces. For instance, Collaborative Spatial Decision-Making (CSDM) tools and Spatial Decision Support Systems (SDSS) fundamentally rely on geographical places to support decision-making [12, 34, 35]. Less attached to the physical property of workspaces, we find synthetic collaborative environments for 
geo-visualization [26, 36, 37]. And we also find proposals combining physical with virtual georeferenced workspaces, like the Geo-Spatial Hypermedia system proposed by Grønbæk et al [26].

Table 1. Major geocollaboration concerns.

\begin{tabular}{|c|c|c|c|c|}
\hline \multirow[t]{7}{*}{ Space } & \multirow[t]{3}{*}{ Place } & \multirow{2}{*}{\multicolumn{2}{|c|}{ Accessibility }} & Same-place, different-place \\
\hline & & & & Co-located, virtually co-located remote \\
\hline & & \multicolumn{2}{|l|}{ Mediation } & rbal cues, rapid feedback, arousal \\
\hline & \multirow{3}{*}{\multicolumn{2}{|c|}{$\begin{array}{l}\text { Geographical } \\
\text { relationships }\end{array}$}} & Location & Cartesian, topological \\
\hline & & & \multicolumn{2}{|c|}{ Distance } \\
\hline & & & \multicolumn{2}{|c|}{ Orientation } \\
\hline & \multicolumn{2}{|l|}{ Awareness } & \multicolumn{2}{|c|}{ Location awareness } \\
\hline \multirow{4}{*}{\multicolumn{2}{|c|}{ Physical space }} & \multirow[t]{4}{*}{ Mobility } & \multicolumn{2}{|c|}{ Wandering, visiting, traveling } \\
\hline & & & \multicolumn{2}{|c|}{$\begin{array}{l}\text { Fixed, mobile, autonomous, free, embedded, } \\
\text { pervasive }\end{array}$} \\
\hline & & & \multicolumn{2}{|c|}{ Flexibility, visibility, context-sensitivity } \\
\hline & & & \multicolumn{2}{|c|}{ Information access } \\
\hline \multirow{6}{*}{\multicolumn{2}{|c|}{ Virtual space }} & \multirow[t]{2}{*}{ Context } & \multicolumn{2}{|c|}{ Focus, nimbus } \\
\hline & & & \multicolumn{2}{|c|}{ Private, public } \\
\hline & & Interaction & \multicolumn{2}{|c|}{ Aggregation, topology, dissemination } \\
\hline & & Navigation & \multicolumn{2}{|c|}{ Spatial, logical } \\
\hline & & $\begin{array}{l}\text { Collaborative } \\
\text { visualization }\end{array}$ & \multicolumn{2}{|c|}{$\begin{array}{l}\text { Data exchange, shared control, dynamic } \\
\text { interaction }\end{array}$} \\
\hline & & Structure & \multicolumn{2}{|c|}{ Clusters, stacks, lists, tables } \\
\hline \multicolumn{2}{|c|}{ Workspace } & $\begin{array}{l}\text { Collaborative } \\
\text { capacity }\end{array}$ & \multicolumn{2}{|c|}{$\begin{array}{l}\text { Individual, collective, coordinated, concerted, } \\
\text { negotiated }\end{array}$} \\
\hline \multirow{2}{*}{\multicolumn{2}{|c|}{$\begin{array}{l}\text { Structured } \\
\text { workspace }\end{array}$}} & $\begin{array}{l}\text { Workspace } \\
\text { awareness }\end{array}$ & Who, wha & vhere, when, how \\
\hline & & $\begin{array}{l}\text { Peripheral } \\
\text { awareness }\end{array}$ & Focus, nir & us, notification, attention \\
\hline & $\begin{array}{l}\text { oreferenced } \\
\text { kspace }\end{array}$ & $\begin{array}{l}\text { Geographical } \\
\text { relationships }\end{array}$ & Location & $\begin{array}{l}\text { Geographical places, synthetic } \\
\text { places, combined places }\end{array}$ \\
\hline & ial space & $\begin{array}{l}\text { Social } \\
\text { awareness }\end{array}$ & Cultural $n$ & ning, history \\
\hline & & Sensemaking & Perceptiol & nterpretation and anticipation \\
\hline & & Embodied in & ion & \\
\hline
\end{tabular}

Antunes et al [2] proposed adopting the notion of collaborative capacity to characterize geocollaboration. Collaborative capacity is a measure of the organizational ability to respond to problems and challenges. The theory was developed by Nunamaker et al [38] and has been tested by other researchers [39-41]. It identifies four levels of increasing ability for successful collaboration, ranging from the individual, collective and coordinated to the concerted level. The theory is that organizations will increase their potential to create value by increasing their collaboration levels. To the four categories we add one more extending the collaborative capacity beyond the concerted level: the negotiated level. The reason to propose this additional level is the observation that the capacity to negotiate conflicting views in concerted work increases the quality of the outcomes [42]. 
Dourish [21] and Brewer and Dourish [43] make the distinction between spatial (structured or georeferenced) and social workspaces, the former more focused on the physical context and the later more adequate to understand broader issues related to social practice beyond the physical reality. In this context, social workplaces combine physical affordances with social interaction, cultural meaning, experience and knowledge.

Weick [44] developed the notion of sensemaking to better understand what occurs in social spaces. Sensemaking is an ongoing process aiming to create order and make retrospective sense of what occurs through the articulation of several cognitive functions like perception, interpretation and anticipation [44]. It has also been associated to collaboration [45] and preliminary decision-making activities like "understanding the situation" or "getting the picture" [46].

Sensemaking is a cognitive function necessary to build awareness of the different elements occurring in the workplace: the team members, their activities and the available physical and virtual artifacts. Sensemaking also serves to build awareness of the relationships between workplaces within workspaces, including geographical relationships and mobility. And finally, sensemaking also contributes to build awareness of the relationships between action and environmental response [47].

Dourish [48] proposed the notion of embodied interaction to account for the embedded relationships between social and spatial spaces. These relationships seem quite common in our everyday experience. Dourish exemplifies with metaphorical expressions like "his position is indefensible" [48], revealing how embedded spatial concepts are in our communication.

From the discussion above we realize that geocollaboration results from a complex interaction between various concepts. Firstly, we shall consider the relationships between place and space, physical and virtual, spatial and social, place and work. Secondly, context and awareness seem fundamental to characterize what may be occurring in spaces, weather physical or virtual. And finally, both mobility and navigation, the former more related with physical spaces and the later more associated to virtual spaces, are also fundamental factors to ponder when analyzing geocollaboration. In Table 1 summarizes the above discussion.

\section{Related Work}

Table 2 summarizes the description of what we regard as the most relevant works in the field of geocolaboration published in the last two years. Most of these works are aimed to support crisis management. Some of them correspond to case studies (noted as $\mathrm{T}$ in Table 2) [7], while others propose applications or prototypes (noted as A/P) including various geocollaboration characteristics like geographical relationships, awareness, mediation and accessibility.

In the table, the $\mathrm{R}$ column shows the work's reference number. $\mathrm{M} / \mathrm{F}$ indicates the field, defined as Knowledge Construction (KC), Decision Making (DM) and Crisis Management (CM). An asterisk in the A/P column indicates the work corresponds to an application or prototype, while an asterisk in the $\mathrm{T}$ column indicates it is an ethnographical study or case analysis identifying application requirements. An 
asterisk in the MD column indicates the work is about mobile devices. The I column indicates the study deals with interaction. $\mathrm{N}$ means the study deals with navigation and V with visualization. Regarding geographic issues, SP indicates users are in the same place and DF in different places. D means the distance between two points is calculated at some stage of the work. An asterisk in column O means the work deals with orientation issues. Regarding awareness issues, $\mathrm{L}$ means the work deals with location, and $\mathrm{S}$ with social awareness. $\mathrm{W}$ and $\mathrm{P}$ indicate the work deal with workspace and peripheral awareness, respectively. Regarding mediation and accessibility, CM means the work proposes or implements co-located mediation, VM virtually colocated mediation, SI synchronous interaction and AI asynchronous interaction.

Table 2. Characterization of selected published research works.

\begin{tabular}{|c|c|c|c|c|c|c|c|c|c|c|c|c|c|c|c|c|c|c|c|}
\hline \multirow{3}{*}{$\mathbf{R}$} & \multirow{3}{*}{$\mathbf{M} / \mathbf{F}$} & \multirow{3}{*}{$\mathbf{A} / \mathbf{P}$} & \multirow{3}{*}{$\mathbf{T}$} & \multicolumn{12}{|c|}{ SPACES } & \multirow{2}{*}{\multicolumn{4}{|c|}{$\begin{array}{c}\text { PLACES } \\
\begin{array}{c}\text { Mediaton and } \\
\text { accessibility }\end{array}\end{array}$}} \\
\hline & & & & \multicolumn{4}{|c|}{ Structure } & \multicolumn{4}{|c|}{$\begin{array}{l}\text { Geographical } \\
\text { relationships }\end{array}$} & \multicolumn{4}{|c|}{ Awareness } & & & & \\
\hline & & & & MD & I & $\mathbf{N}$ & $\mathbf{V}$ & SP & DP & D & $\mathbf{O}$ & $\mathbf{L}$ & $\mathbf{S}$ & $\mathbf{W}$ & $\mathbf{P}$ & CM & VM & SI & AI \\
\hline$[8]$ & $\mathrm{KC}$ & $*$ & & $?$ & * & * & * & & $*$ & $*$ & * & * & $*$ & * & $*$ & & * & $*$ & \\
\hline$[4]$ & DM & $*$ & & & $*$ & $*$ & & & $*$ & & & & & & & & $*$ & $*$ & \\
\hline$[9]$ & $\mathrm{CM}$ & & $*$ & & $*$ & & & & $*$ & & & * & & $*$ & $*$ & & & $*$ & $*$ \\
\hline$[1]$ & DM & $*$ & & & $*$ & & $*$ & $*$ & & $*$ & $*$ & * & & $*$ & & $*$ & & $*$ & \\
\hline [50] & $\mathrm{CM}$ & & $*$ & * & $*$ & * & & & $*$ & & & & & & $*$ & & & $*$ & \\
\hline [49] & $\mathrm{CM}$ & & $*$ & $*$ & & $*$ & & & $*$ & & & $*$ & & & & & & & $*$ \\
\hline [51] & $\mathrm{CM}$ & $*$ & & & $*$ & $*$ & * & & $*$ & & & & & & $*$ & & & $*$ & \\
\hline [6] & $\mathrm{CM}$ & & $*$ & $*$ & $*$ & $*$ & $*$ & & $*$ & & & $*$ & & $*$ & & & & $*$ & $*$ \\
\hline & $\#$ & 4 & 4 & 4 & 7 & 6 & 4 & 1 & 7 & 2 & 2 & 5 & 1 & 4 & 4 & 1 & 2 & 7 & 3 \\
\hline
\end{tabular}

Half of the works referenced in Table 1 adopt mobile devices to capture data in the field, while a central server processes and aggregates this information. On the other hand, half of the works describe a proposal rather than a concrete application $[3,6$, $49,50]$. Only one of the works describes an application where users work in the same place, thus supporting co-located mediation. The works described in $[6,50,51]$, propose theoretical models where data is gathered in the field and synchronized in a central server. Most of the works are meant for people working in different places and only two of them use GPS to mark physical locations. Only one work considers social awareness. Regarding mediation and accessibility, two works consider virtual mediation, most of them synchronous.

Most works stress the importance of designing simple user-interfaces and some of them suggest including speech recognition $[52,53]$. Most works adopt gestures to control the system functionality, including marking locations on maps, identifying and associating the users' comments and building awareness [7].

Other surveyed works, not shown on Table 2 for conciseness, describe the advantages of using synchronously connected mobile devices with other physically or virtually distributed systems. eMapBoard [5], is a geo-collaboration tool for disaster management offering real-time analysis components. It implements a client/server architecture and is intended to be used in control centers. Hence, it lacks the support 
for mobile devices. GeoMAC (Geospatial Multi-Agency Coordination Group) is a web-based tool originally designed for fire managers accessing online maps of current fire locations and perimeters [54]. Detailed real-time information cannot be provided and it does not allow distributed collaboration. Toucan Navigate (http:www.infopatterns.com) is a P2P-based collaborative geographic information system allowing whole teams to concurrently interact with a map regardless of the physical location of its members. The annotations over the map are shared and updated automatically. However, it does not support mobile on-field operators. GeoConference allows exploiting geographic data using standard services. In a geoconference, participants share information in a synchronized geo-referenced workspace [55]. The GeoConference system includes tools to manage users, workgroups and geo-data access. It is mainly used in control centers and no real support for mobility is provided. ArcPAD is a mobile client/server GIS product developed by ESRI4. ArcPAD uses handheld and mobile devices, and provides field operators with the ability to capture, analyze, and display geographic information [56]. It cannot be used for ad-hoc and on-field collaboration.

\section{Introducing a Geocollaboration Model}

The proposed geocollaboration model is organized in two ladders (see Figure 1). The first ladder defines places. In general terms, places deal with accessibility and mediation. We define places as a combination of three model elements: teams, tasks and artifacts. Teams of co-workers manipulate artifacts to accomplish tasks.

The artifacts may be physical or virtual. We regard the manipulation of artifacts in a working context not an end in itself but a mean to manage the knowledge necessary to accomplish tasks. A place is therefore where the work is being done: a team accomplishes a particular task using some specific artifacts in a place. In this ladder we do not relate the notion of place with the physical location of the team.

In the second ladder we consider space. Spaces contain multiple places and the corresponding teams, artifacts and tasks. Spaces bring additional context to the above elements. We organize these contextual elements in four major categories: virtual, physical, social and awareness elements. Concerning the virtual properties, they fundamentally define artifacts according to structure, interaction, navigation and visualization.

The physical properties such as location, distance, orientation and mobility may characterize teams and tasks. If all team members are in the same physical place, then the place is co-located. If they are in different physical places and work in different tasks, then the places are remote. And if the team is dispersed across different physical locations but working in the same task, then the place is virtually co-located. This combination of elements is sufficiently abstract and flexible to afford the most common logical and physical arrangements that we find in CSCW.

Regarding mobility, we consider the team members may either be fixed or wandering around the space. The artifacts may be fixed in one place, mobile or pervasive in the whole space.

Spaces also deal with the social dimension, including collaborative capacity, 
sensemaking and embodied interaction. We realize that collaborative capacity has a significant impact in teams, tasks and artifacts. Teams with more collaborative capacity need shared artifacts to organize their work places according to increasing levels of communication, interaction, coordination, collaboration and negotiation support. The impact of this view is mostly associated with tasks and artifacts: designing more collaborative artifacts will support more collaborative tasks, and should consequently lead to an increased collaborative capacity [2].

Still regarding the social dimension, we realize that sensemaking concerns the articulation of teams, tasks and artifacts. Sensemakers will explore different work arrangements in spaces and places, moving around artifacts in dynamic and exploratory ways. Weick [47] illustrates this type of behavior with the example of bringing an airplane back to an aircraft carrier, where several people working in different places must contribute to complete successfully the operation.

We regard the sensemaking function in conjunction with collaborative capacity: sensemaking may be individual or collective, but we posit the collective construction of sensemaking will lead to increased organizational ability to make sense of the ongoing situations. And we finally emphasize that artifacts are instrumental to support increasing levels of sensemaking, from individual to collective.

In our model, the notion of embodied interaction is mostly attached to physical artifacts and the technology they provide to support communication, collaboration, mobility, and obtaining information from and about the environment.

Finally, we consider the relationship between space and awareness. In the proposed model, awareness concerns understanding who are the team members, where and what tasks are being performed, what artifacts are being manipulated, and what relationships are established between places and geographical locations.

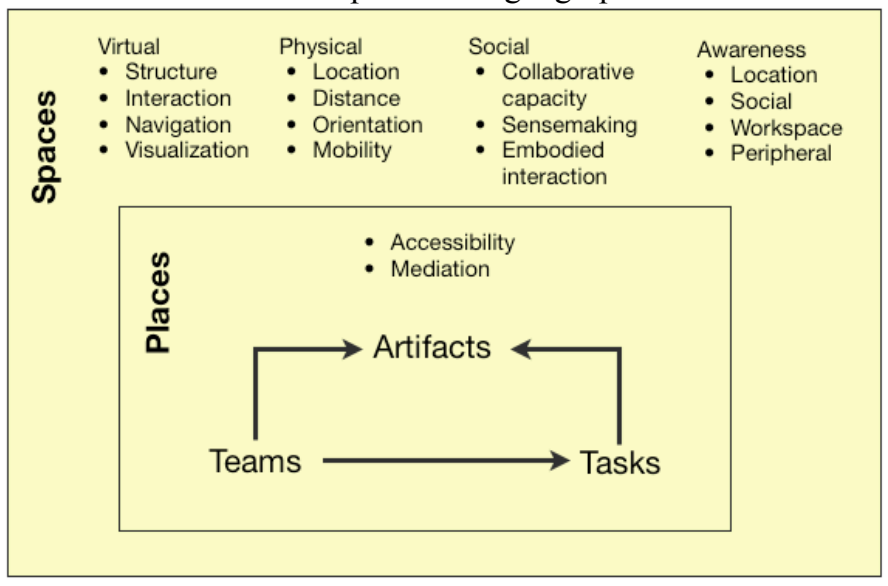

Fig. 1. geocollaboration model

The two ladders previously described allow us to define a design process in two complementary steps. The first ladder assumes a descriptive view that we consider instrumental to analyze the "as-is" work situation:

- Identifying the work elements: Who are the team members? Which tasks they accomplish? Which are the relevant work places and spaces? Which artifacts are used? 
- Identifying their relationships: What tasks the team members accomplish? What artifacts they manipulate to accomplish specific tasks? In what workplaces and workspaces reside the artifacts? How the team members, artifacts and tasks move around spaces?

Then, the second ladder departs from the "as-is" to analyze the "to-be" situation. This step leads the designer towards analyzing how artifacts may develop:

- Collaborative capacity: What is the current level of collaborative capacity? How to develop artifacts with increased collaborative capacity?

- Sensemaking: What is the current level of sensemaking? How to increase sensemaking?

- Awareness: Do artifacts support the diversity of location, social, workspace and peripheral awareness? How can awareness be improved?

In Figure 1 we summarize the fundamental constructs of the proposed geocollaboration model. We note artifacts emerge as the central model element, not only because they are responsible for articulating teams, tasks, places and spaces, but because they became responsible for increasing awareness and collaboration support.

\section{Applications}

In this section we describe two application developments using the geocolaboration model presented in the previous section.

\subsection{Redesigning a geological inventory process}

This case concerns work redesign at a public agency responsible for inventorying and valuing the Portuguese geological resources. The core activities of this agency include studying and mapping the existing resources, developing risk maps, and producing geographical information systems. The case study was focused on the geological inventory process.

The geocollaboration model organizes the analysis in two ladders. This structured approach was followed by the case study. The first ladder was defined during interviews with several experts from the agency. We identified two workplaces: the office and the field. In general, the inventory process requires multiple visits to the field to elicit various types of data, intertwined with consolidation activities done in the office. The visits to the field tend to be done by one single person, while the office activities combine individual and collaborative work.

The work arrangement was therefore structured around two different spaces (office and the field) and two different places (visit and consolidation) having one-to-one relationships. Indeed, the inventory process seemed highly dependent on the relationship between place and space: many activities, such as determining the land structure, are mostly done in the physical space, as the experts often need to move around to analyze different cues to determine the exact land structure. But the activities are also highly dependent on the notion of place, especially in what regards confronting the opinions from experts in different fields, such as paleontology, petrology or sedimentology, which are done when consolidating work in the office. 
We then continued the study by observing and inquiring people working in the field. We analyzed the artifacts used by the experts. Work in the field is centered on two artifacts: the field book and the combination of a map with a transparent overlay. The map/overlay allows representing the inventory data, while the field book serves to annotate supplementary information, including doubts and concerns.

Finally, in the second ladder, we analyzed the sensemaking and collaborative capacity of the artifacts used by the target organization. We realized several critical issues were hampering sensemaking:

- Whenever doubts occur, workers have to switch places, either because they lack physical context (e.g., to triangulate different physical evidence) or social context (to triangulate with different experts).

- It was often difficult to use the book outside the field, because it would loose context. While consolidating in the office, workers need to reconstitute the visit to put back in context the data recorded in the field book.

- Information was scattered between the field book and map/overlay, which were difficult to co-relate.

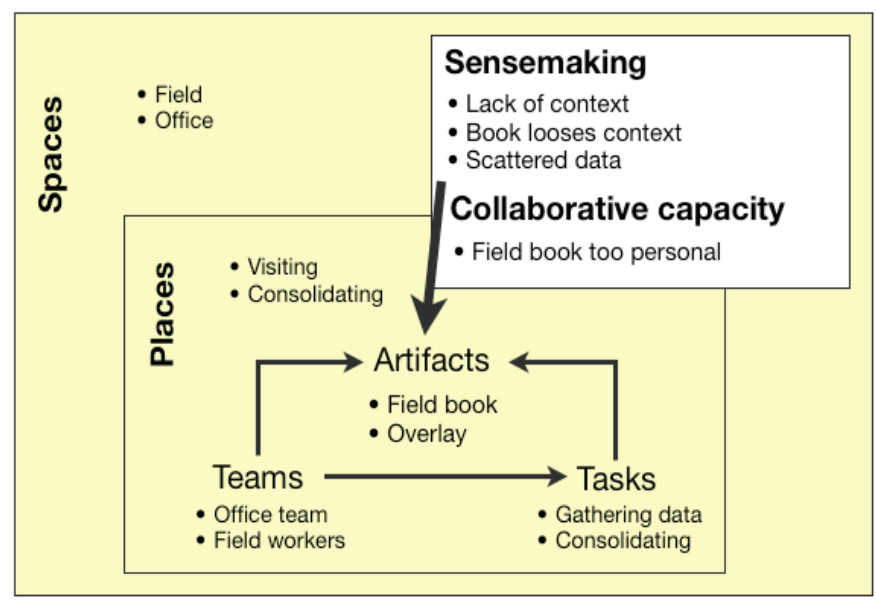

Fig. 2 - Summary analysis of the geological inventory process

Regarding collaborative capacity, we also realized the field book is inherently a personal artifact, which looses value when working as a team in the office. The analysis of the geological inventory process is presented in Figure 2. Based on this analysis, we then defined our major technology requirements for work redesign:

- Sharing the field book with the purpose to increase collaborative capacity.

- Integrating the field book with the map/overlay, aiming to increase sensemaking.

- Integrating the two places, visit and consolidation, bringing all relevant stakeholders together to resolve problems as they appear in the field and in the office, aiming again to increase collaborative capacity. This required integrating communication mechanisms (audio and instant text messaging) with the field book.

These requirements lead us to develop a prototype, running on tablet and common PCs, integrating the field book and map/overlay (see Figure 3). This prototype also 
merged the visit and consolidation activities into one single place distributed across two different spaces: field and office. This allowed the field workers, using tablet PCs, to get in contact with the office workers and immediately exchanging comments on any occurring problems or doubts.

The prototype supports data exchange, shared control and dynamic interaction. It also integrates GPS with instant text messaging. The exchanged instant text messages are preserved in the field book with automatic associations to the geographical position of the field workers, thus keeping the doubts, comments or opinions in their proper context. Because many doubts are resolved in the field, there is less chance to swing back and forth between the office and the field.

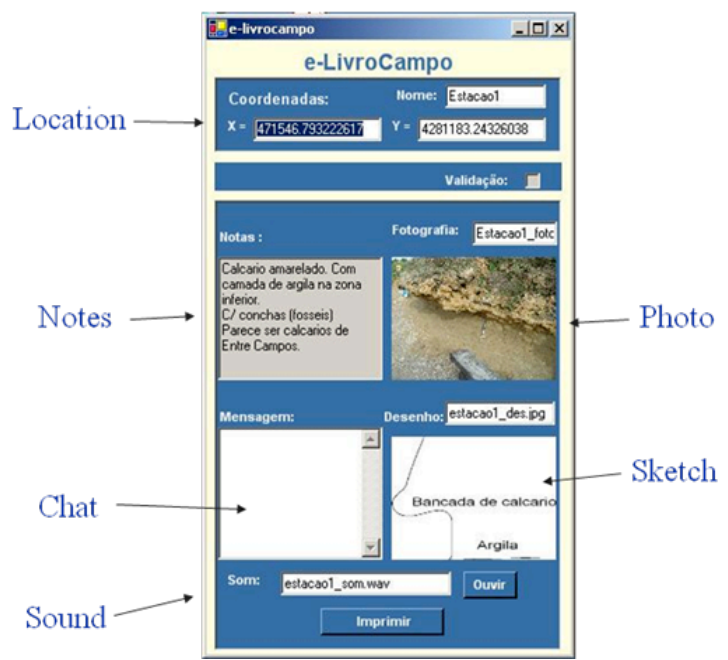

Fig. 3 - Developed prototype for application 1

The prototype was evaluated with a field test and contextual interviews with several experts from the agency. The obtained results indicate that the system increased sensemaking and collaborative capability. Related to sensemaking, the participants regarded very positively the expeditious way to locate points and associate them in the field book. Related with collaborative capability, the participants were extremely favorable to the communication between field and office workers, effectively resolving problems occurring in the field and thus simplifying the whole inventory process. More details about this case study can be found in [2].

\subsection{Supporting the evacuation of crowded places}

This case concerns supporting the police evacuating people from a stadium or any other facility with capacity for hosting thousands of people. The major problems to consider are finding adequate evacuation routes, spreading out people in congested places such as bus and/or metro stations and parking places, and dealing with highdensity and fluid crowds. These are frequent problems faced by the police in Santiago de Chile, where sports fields with capacity for 80.000 people were built in surroundings close to the city limits and now surrounded by busy streets and dense 
inhabited city quarters. In these events, the police will place agents in strategic places to patrol people coming out from the sports field, showing them the planned evacuation ways.

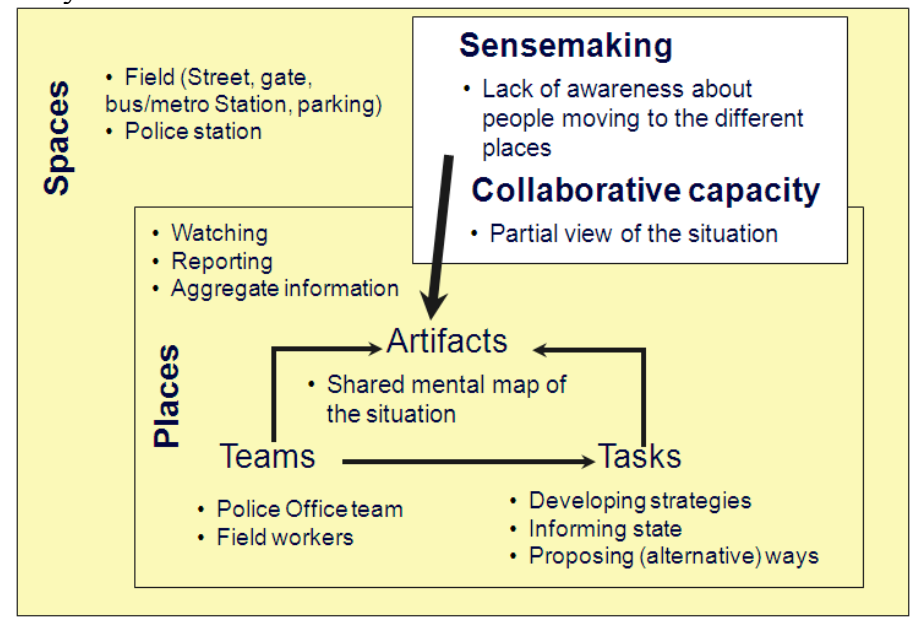

Fig. 4 - Summary analysis of the evacuation process

Normally, each agent will have a radio device through which he/she will report the situation context to the central police station and colleagues. The agents in the central police station try to make a picture of the whole situation based on the scattered information provided verbally by the agent. The central police station will give commands to the agents in the field, managing any exceptional situations that may occur.

This is a typical geocollaboration situation where location and collaboration are of critical importance. Analyzing the situation, in the first ladder we defined two spaces: police station and field. The workplaces are the police station and some strategic points in the field: stadium gates, streets, parking places, bus and metro stations. In the field, agents have to watch the emergent situations, report them to the central station and give instructions to the mob.

The main sensemaking task here is building a shared mental map of the situation, understanding the whole picture and anticipating events. This mental map is also the artifact used to communicate with each other. We detect here a main problem hampering this task: sometimes the exchange of voice information does not allow everyone to communicate accurately, timely and within context. Also, the whole context may only be assembled in the central station, often with many delays. The summary analysis of the evacuation scenario is presented in Figure 4. As we see, the central shared artifact is the area map. This map is situated at the central police station and is annotated according to the information people on the field submit by voice. 


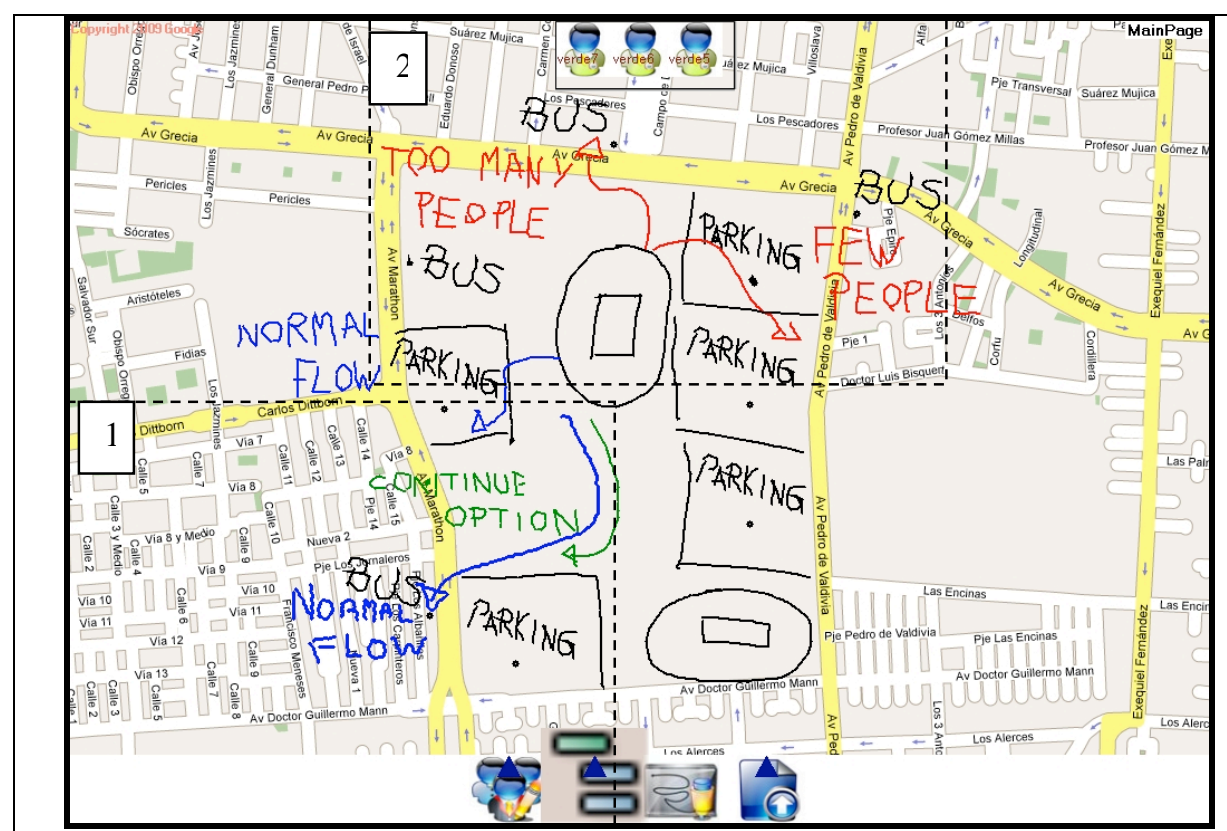

Map it the central police station, displayed in a large interactive screen

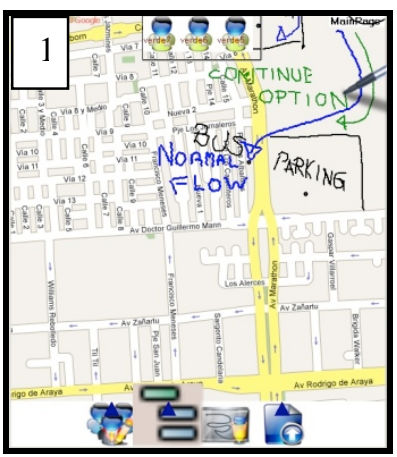

Map in police's PDA1

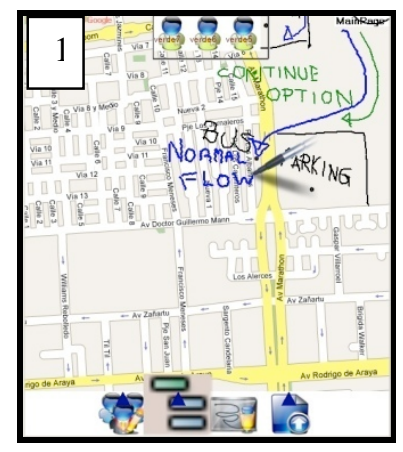

Map in police's PDA2

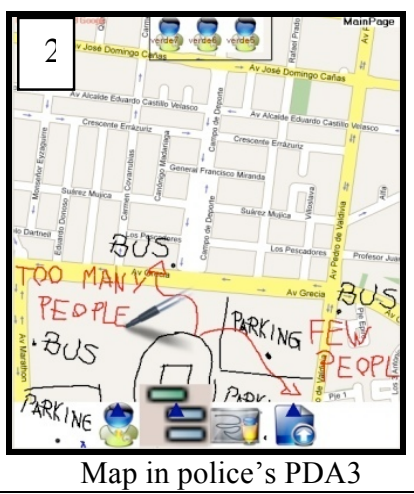

Fig. 5 - Developed prototype for application 2

We designed a distributed application to support this activity, allowing agents in the police station to display the map on a big touch-sensitive screen showing the sports field and surrounding areas. The map may be annotated with freehand writing and sketching. Each agent in the field has a portable device, also touch sensitive, showing the portion of the map where she/he is located, which they can also annotate. The map is automatically adjusted according to the agent's position thanks to an incorporated GPS. All applications (the one running in the police station and those running in mobile devices) are synchronized, so that any annotations done in one application will be immediately shown in the others. In Figure 5 we may see some screenshots showing the map available in the police station (upper section) and the 
mobile devices of three agents in the field (lower section). Another design element focusing on awareness concerns the areas marked and labeled with a number, indicating what areas the agents in the field are controlling. In this way the agents in the station may perceive the whole control of the situation. Furthermore, the agents may synchronize their portion of the map with another agent. This supports the collaboration of two (or more) agents in charge of the same geographical area. In Figure 5 we see that policeman 1 and policeman 2 are working synchronized in the area labeled as 1 . This prototype is currently being developed and there is still no data from formal evaluation available.

\section{Discussion}

This paper proposes a model for designing geocollaborative applications. The model considers the main design goal is supporting a team in the collaborative construction of a shared vision about the relevant conditions in a certain geographical area, in situations where this vision is critical for team members to accomplish their task. The model is based on a set of foundational concepts, including teams, tasks, places, spaces, and artifacts. Artifacts emerge as the central model element, not only because they are responsible for articulating teams, tasks, places and spaces, but also because they are responsible for increasing sensemaking and collaborative capacity.

In order to test the model flexibility and completeness, we used it to design two quite different applications. The model provided guidelines that helped analyzing and articulating the geocollaborative requirements of those applications.

Moreover, the proposed model also allows describing various geocollaboration applications in a uniform and standardized way, and therefore facilitates their benchmarking and classification. In addition, the proposed model allows identifying the major software components and libraries necessary to integrate the geocollaborative elements proposed in the model. Some of these software components have already been developed to implement the applications described in the paper and constitute the basis of a future geocollaborative software platform.

The proposed model may also serve to lay out the conceptual framework necessary to characterize two emerging types of tools: e-planning and e-participation. The aim of e-planning and e-participation is to engage people living in a region or urban area to participate in government decisions and urban planning.

Acknowledgements. This paper was supported by the Portuguese Foundation for Science and Technology (PTDC/EIA/67589/2006) and Fondecyt 1085010.

\section{References}

1. MacEachren, A., Guoray, C., Brewer, I., Chen, J.: Supporting Map-Based geocollaboration through Natural Interfaces to Large-Screen Displays. Cartographic Perspectives 54 (2006) 4-22. 
2. Omitted to allow blind review: A Conceptual Framework for the Design of GeoCollaborative Systems. Group Decision and Negotiation 15 (2006) 273-295.

3. Cai, G.: Extending Distributed GIS to Support Geo-Collaborative Crisis Management. Progress in Human Geography 25 (2001).

4. Rinner, C.: Argumentation Mapping in Collaborative Spatial Decision Making. Collaborative GIS. Idea Group Publishing (2006) 85-102.

5. MacEachren, A., Guoray, C., Brewer, I., Chen, J.: Visually Enabled geocollaboration to Support Data Exploration \& Decision Making. Procs. of the 21st International Cartographic Conference, Durban, South Africa (2003) 10-16.

6. Capata, A., Marella, A., Russo, R.: A Geo-Based Application for the Managemnt of Mobile Actors During Crisis Situations. Proceedings of the 5th International ISCRAM Conference, Washington DC, US (2008).

7. Schafer, W., Ganoe, C., Caroll, C.: Supporting Community Emergency Management Planning through a geocollaboration Software Architecture. Computer Supported Cooperative Work 16 (2007) 501-537.

8. Convertino, G., Ganoe, C., Schafer, W., Yost, B., Carroll, J.: A Multiple View Approach to Support Common Ground in Distributed and Synchronous Geo-Collaboration. Proceedings of Third International Conference on Coordinated and Multiple Views in Exploratory Visualization (2005) 121-132.

9. Convertino, G., Zhao, D., Ganoe, C., Carroll, J., Rosson, M.: A Role-Based Multiple View Approach to Distributed Geo-Collaboration. Human-Computer Interaction 4553 (2007) 561-570.

10. MacEachren, A., Cai, G., Sharma, R., Rauschert, I., Brewer, I., Bolelli, L., Shaparenko, B., Fuhrmann, S., Wang, H.: Enabling Collaborative Geoinformation Access and Decision Making through a Natural, Mulimodal Interface. International Journal of Geographical Information Science 19 (2005) 293-317.

11. Johansen, R., Sibbet, D., Benson, S., Martin, A., Mittman, R., Saffo, P.: Leading Business Teams. Addison-Wesley (1991).

12. MacEachren, A., Brewer, I.: Developing a Conceptual Framework for Visually-Enabled geocollaboration. International Journal of Geographical Information Science 18 (2004) 134.

13. DeSanctis, G., Gallupe, R.: A Foundation for the Study of Group Decision Support Systems. Management Science 33 (1987) 589-609.

14. Sharifi, S., Pawar, K.: Virtually Co-Located Product Design Teams. International Journal of Operations \& Production Management 22 (2002) 656-679.

15. Rodden, T., Blair, G.: CSCW and Distributed Systems: The Problem of Control. Proceedings of the Second Conference on European Conference on Computer-Supported Cooperative Work. Kluwer Academic Publishers, Amsterdam, The Netherlands (1991) 4964.

16. Kim, T., Chang, A., Holland, L., Pentland, A.: Meeting Mediator: Enhancing Group Collaborationusing Sociometric Feedback. Proceedings of the ACM 2008 Conference on Computer Supported Cooperative Work. ACM Press, San Diego, CA (2008) 457-466.

17. Daft, R., Lengel, R.: Organizational Information Requirements, Media Richness and Structural Design. Management Science 32 (1986).

18. Kock, N.: Media Richness or Media Naturalness? The Evolution of Our Biological Communication Apparatus and Its Influence on Our Behavior toward E-Communication Tools. IEEE Transactions on Professional Communications 48 (2005) 117-130.

19. Dix, A., Rodden, T., Davies, N., Trevor, J., Friday, A., Palfreyman, K.: Exploiting Space and Location as a Design Framework for Interactive Mobile Systems. ACM Transactions on CHI 7 (2000). 
20. Harrison, S., Dourish, P.: The Roles of Place and Space in Collaborative Systems. Proceedings of the 1996 ACM conference on Computer supported cooperative work. ACM Press, Boston, Massachusetts (1996) 67-76.

21. Dourish, P.: Re-Space-Ing Place: "Place" And "Space" Ten Years On. Proceedings of the 2006 20th Anniversary Conference on Computer Supported Cooperative Work. ACM Press, Alberta, Canada (2006) 299-308.

22. Rodden, T.: Populating the Application: A Model of Awareness for Cooperative Applications. Proceedings of the 1996 ACM Conference on Computer Supported Cooperative Work. ACM Press, Boston, Massachusetts (1996) 87-96.

23. Greenberg, S., Boyle, M., Laberge, J.: PDAs and Shared Public Displays: Making Personal Information Public, and Public Information Personal. Personal Technologies 3 (1999) 5464.

24. Snowdon, D., Munro, A. (eds.): Collaborative Virtual Environments: Digital Places and Spaces for Interaction. Springer-Verlag, New York (2000).

25. Greenberg, S., Roseman, M.: Using a Room Metaphor to Ease Transitions in Groupware. Ackerman, M., Pipek, V., Wulf, V. (eds.): Sharing Expertise. Beyond Knowledge Management. The MIT Press, Cambridge, MA (2003) 203-256.

26. Grønbæk, K., Vestergaard, P., Ørbæk, P.: Towards Geo-Spatial Hypermedia: Concepts and Prototype Implementation. Proceedings of the thirteenth ACM conference on Hypertext and hypermedia. ACM Press, College Park, Maryland (2002) 117-126.

27. Brewer, I., MacEachren, A., Abdo, H., Gundrum, J., Otto, G.: Collaborative Geographic Visualization: Enabling Shared Understanding of Environmental Processes. Proceedings of IEEE Symposium on Information Visualization, Washington DC, US (2000) 137.

28. Kristoffersen, S., Ljungberg, F.: Your Mobile Computer Is a Stationary Computer. CSCW'98 Handheld CSCW Workshop, Seattle (1998).

29. Cheverst, K., Davies, N., Mitchell, K., Friday, A., Efstratiou, C.: Developing a ContextAware Electronic Tourist Guide: Some Issues and Experiences. Proceedings of the SIGCHI Conference on Human Factors in Computing Systems. ACM Press, The Hague, The Netherlands (2000) 17-24.

30. Davis, G.: Anytime/Anyplace Computing and the Future of Knowledge Work. Communications of ACM 45 (2002) 67-73.

31. Koch, M., Koch, J.: Application of Frameworks in Groupware-the Iris Group Editor Environment. ACM Computing Surveys (CSUR) 32 (2000).

32. Liechti, O.: Supporting Social Awareness on the World Wide Web with the Handheld Cyberwindow. Workshop on Handheld CSCW at CSCW '98, Seattle, US (1998).

33. Gutwin, C., Greenberg, S.: The Effects of Workspace Awareness Support on the Usability of Real-Time Distributed Groupware. ACM Transactions on Computer-Human Interaction 6 (1999) 243-281.

34. Nyerges, T., Montejano, R., Oshiro, C., Dadswell, M.: Group-Based Geographic Information Systems for Transportation Site Selection. Transportation Research C 5 (1997) 349-369.

35. Armstrong, M.: Requirements for the Development of GIS-Based Group Decision Support Systems. Journal of the American Society for Information Science 45 (1994) 669-677.

36. Manoharan, T., Taylor, H., Gardiner, P.: A Collaborative Analysis Tool for Visualisation and Interaction with Spatial Data. Proceeding of the seventh international conference on 3D Web technology, Tempe, Arizona (2002) 75-83.

37. MacEachren, A., Edsall, R., Haug, D., Baxter, R., Otto, G., Masters, R., Fuhrmann, S., Qian, L.: Virtual Environments for Geographic Visualization: Potential and Challenges. Procs. of the 1999 workshop on new paradigms in information visualization and manipulation. ACM Press, Kansas City, Missouri (1999) 35-40. 
38. Nunamaker, J., Romano, N., Briggs, R.: Increasing Intellectual Bandwidth: Generating Value from Intellectual Capital with Information Technology. Group Decision and Negotiation 11 (2002) 69-86.

39. Bach, C., Belardo, S., Faerman, S.: Employing the Intellectual Bandwidth Model to Measure Value Creation in Collaborative Environments. Proceeding of the 37th Hawaii International Conference on System Sciences, Hawaii (2004).

40. Qureshi, S., Briggs, R.: Revision the Intellectual Bandwidth Model and Exploring Its Use by a Corporate Management Team. Proceeding of the 36th Hawaii International Conference on System Sciences, Hawaii (2003).

41. Qureshi, S., Vaart, A., Kaulingfreeks, G., Vreede, G., Briggs, R., Nunamaker, J.: What Does It Mean for an Organization to Be Intelligent? Measuring Intellectual Bandwidth for Value Creation. Proceeding of the 35th Hawaii International Conference on System Sciences, Hawaii (2002).

42. Omitted to allow blind review.: Addressing the Conflicting Dimension of Groupware: A Case Study in Software Requirements Validation. Computing and Informatics 25 (2006) 523-546.

43. Brewer, J., Dourish, P.: Storied Spaces: Cultural Accounts of Mobility, Technology, and Environmental Knowing. International Journal of Human-Computer Studies 66 (2008) 963976.

44. Weick, K.: The Collapse of Sensemaking in Organizations: The Mann Gulch Disaster. Administrative Science Quarterly 38 (1993) 628-652.

45. Larsson, A.: Making Sense of Collaboration: The Challenge of Thinking Together in Global Design Teams. Proceedings of the 2003 international ACM SIGGROUP conference on Supporting group work. ACM Press, Sanibel Island, Florida (2003) 153-160.

46. Hasan, H., Gould, E.: Support for the Sense-Making Activity of Managers. Decision Support Systems 31 (2001) 71-86.

47. Weick, K.: Making Sense of the Organization. Blackwell, Oxford, UK (2001).

48. Dourish, P.: Where the Action Is. The MIT Press, Cambridge, MS (2001).

49. Malizia, A., Astorga, F., Onorati, T., Díaz, P., Aedo, I.: Emergency Alerts for All: An Ontology Based Approach to Improve Accessibility in Emergency Alerting Systems. Proceedings of the 5th International ISCRAM Conference (2008).

50. Bortenschlager, M., Leitinger, S., Rieser, H., Steinmann, R.: Towards a P2P-Based geocollaboration System for Disaster Management. GI-Days 2007 - Young Researchers Forum (2007)

51. Convertino, G., Mentis, H., Bhambare, P., Ferro, C., Carroll, J., Rosson, M.: Comparing Media in Emmergency Planning. Proceedings of the 5th International ISCRAM Conference, Washington DC, US (2008).

52. Sharma, R., Yeasin, M., Krahnstoever, N., Rauschert, I., Cai, G., I., B., Maceachren, A., Sengupta, K.: Speech-Gesture Driven Multimodal Interfaces for Crisis Management. Proceedings of the IEEE special issue on Multimodal Human-Computer Interface 91 (2003) 1327-1354.

53. Fuhrmann, S., MacEachren, A., Dou, J., Wang, K., Cox, A.: Gesture and Speech- Based Maps to Support Use of GIS for Crisis Management: A User Study. AutoCarto 2005, Las Vegas, US (2005).

54. Wagtendon, J., Zhu, Z., Lile, E.: Appendix E - White Paper on Pre-Fire Risk Assessment and Fuels Mapping. (2004).

55. Siegel, C., Fortin, D., Pellerin, E.: Bringing Geospatial Expertise to Emergency Operations Management with Geoconferencing. Proceedings of the 98th Conference of the Canadian Institute of Geomatics, Ottawa, Canada (2005).

56. ESRI: Arcgis 9, Arcpad Reference Guide. USA (2005). 